\title{
ROCA MARTÍNEZ, BELTRÁN (2013) Contrapoder sindical. Etnografía, crítica e investigación aplicada en las organizaciones sindicales. Madrid: Fundación de Estudios Libertarios Anselmo Lorenzo. 113 pp.
}

\author{
Ángel del Río Sánchez \\ Universidad Pablo de Olavide
}

El libro que presentamos supone una magnífica aportación crítica desdela Antropología al estudio sobre el movimiento sindical. Y esto a la vez supone una novedad porque tal como avisa su autor, Beltrán Roca, no ha habido un interés investigador desde esta disciplina por abordar esta temática a pesar de su indudable presencia social contemporánea. Salvo unas pocas e interesantes excepciones apuntadas, todas ellas en Andalucía, (Félix Talego, Fernando Ventura, José Luis Gutiérrez, David Florido y el propio Beltrán Roca) el mundo de las relaciones laborales y las organizaciones sindicales ha carecido de investigaciones con un enfoque etnográfico que pudieran aportar nuevas visiones a las más recurrentes de otras disciplinas como el Derecho, la Sociología o la Politología que centran el objeto de estudio del movimiento sindical en su función como grupos de presión que tratan de intervenir en las políticas públicas, obviando otras realidades y potencialidades de mayor calado. Y ello lo atribuye a la imagen fomentada desde el dogma neoliberal que presenta a los sindicatos como actor social menor y decadente con estructuras caducas, fuertemente dependientes del Estado, indiferenciadas unas de otras, desarticuladas y poco representativas.

El antropólogo Beltrán Roca, resistiéndose a todos estos artificios interesados que tratan de cuestionar la centralidad del trabajo y debilitar el papel del movimiento sindical, y sin cuestionar la actual crisis de legitimidad de los sindicatos (especialmente de las 
grandes centrales sindicales), se siente interpelado en su doble condición de investigador y sindicalista comprometido, para tratar de desentrañar desde el método etnográfico, la reflexión política y la investigación aplicada las claves que permitan a lo que denomina "sindicalismo de oposición" ganar espacios en el mundo del trabajo. Y lo hace "desde la convicción de que es preciso cambiar muchas cosas en el movimiento sindical, romper con ciertas 'reglas del juego', para regenerar un sindicalismo de oposición, un sindicalismo capaz de transformar estructuras sociales que generan la injusticia” (pp.11-12).

Como fruto de este noble empeño surge este ensayo que la Fundación de Estudios Libertarios Anselmo Lorenzo, siempre atento para dar cobertura a las voces críticas y alternativas, ha publicado con el significativo título "Contrapoder sindical. Etnografía, crítica e investigación aplicada en las organizaciones sindicales". El libro se divide en cuatro capítulos, todos ellos ideados con una doble vertiente analítica y descriptiva: uno primero contextual, dos dedicados a sendos estudios etnográficos y un cuarto de síntesis y con un cariz propositivo.

En el primer capítulo titualdo "Poder y representatividad sindical" el autor analiza de manera muy gráfica el sistema español de relaciones laborales comparándolo con otros modelos existentes en Europa. Es de sumo interés seguir el análisis de la evolución del movimiento sindical desde el franquismo hasta nuestros días. Beltrán opina que la actual crisis del sindicalismo tiene su origen en la llamada transición a la democracia. Es en esta etapa donde se fragua el sistema de relaciones laborales que privilegia la presencia de unos grandes sindicatos domesticados (sindicalismo de Estado) y arrincona a aquellos que mostraban una actitud más combativa, caso de la CNT (sindicalismo de oposición), que no aceptan las nuevas reglas de juego impuestas por los partidos que protagonizaron la transición. En aras de una "consolidación democrática" y como ocurriría con otros movimientos sociales -especialmente el ciudadano y vecinal- que habían desempeñado un importante papel en la extensión de la lucha contra la dictadura, los grandes sindicatos al amparo de los principales partidos de la izquierda, optan por alcanzar grandes pactos con los nuevos gobiernos y las organizaciones empresariales desactivando, de este modo, todo su potencial transformador. El proceso de institucionalización que se consagra en las décadas de 1980 y 1990 nos lega un sindicalismo mayoritario con dos características fundamentales: la práctica de la democracia delegada a través de elecciones sindicales y comités de empresa y la existencia de un generoso sistema de financiación pública. Aún así, cabe señalar la acción de otras formas de concebir el sindicalismo representado en organizaciones minoritarias (CNT, SAT y otras) que aspiran a cambiar unas reglas del juego que desvirtúan las luchas emancipatorias de las clases subalternas.

En el segundo capítulo, "Desmovilización y Sindicalismo de Estado: etnografía de un conflicto sindical", colabora Fernando Ventura, uno de los referentes en el estudio del movimiento sindical desdela Antropología. El capítulo aborda desde el método etnográfico 
un conflicto laboral en un hospital sevillano. La etnografía, presentada con extraordinaria minuciosidad descriptiva, prestancia y hasta un distendido toque de humor, sirve a los autores para reflexionar en torno a las relaciones entre democracia y sociedad civil en el marco de una lucha laboral que inician un grupo de mujeres del sindicato de sanidad de CCOO. La justa reivindicación de las trabajadoras activa todo el complejo y jerarquico engranaje sindical y de relaciones con la Administración con todos los rituales y liturgia de la acción sindical (asambleas, manifestaciones, encierros, negociaciones... ). El lúcido análisis de Roca y Ventura permite entender ciertas perversiones del sindicalismo de Estado cuyo poder se asienta, en última instancia, en su capacidad de desmovilización, amparándose en la reivindicación obrera como combustible para la autolegitimación. Bajo este principio, se extiende y justifica la imagen dentro de la burocracia sindical del trabajadorcomo ser alienado, pasivo, no participativo, etc. sin tener en cuenta las causas que determinan tal situación.

En el capítulo tercero, "Sindicalismo, acción directa y cambio social" aparece Beltrán Roca como activista participando, en un plano secundario, en una acción directa en la huelga de mujeres de la limpieza de una universidad pública sevillana. La acción de un grupo de trabajadoras aparentemente despolitizado que optaron por el sindicato anarcosindicalista CNT como platoforma de reivindicación (equiparación salarial con las trabajadoras de la otra universidad sevillana), una vez que el sindicato mayoritario se alineaba con la empresa, lleva a Beltrán Roca a reflexionar sobre ciertas categorías conceptuales atendidas especialmente por el pensamiento libertario. Amparándose en las enseñanzas de pensadores emblemáticos como Malatesta y Bakunin, y autores contemporáneos como Gavin Grindon, David Graeber y Andrej Grubacic entre otros, desentraña la capacidad pedagógica, transgresora, transformadora y poética de la acción directa y relacionada con esta, la política prefigurativa que incide en la ética de la lucha contra las injusticias como conquista plena de la libertad: "la libertad solo existe en el momento de la revolución. Y esos momentos no son tan excepcionales como piensas" apuntan los antropólogos Graeber y Grubacic (p. 77). Las trabajadoras de la limpieza a través de su acción consiguieron una visibilización hasta entonces inexistente, y fue acto de empoderamiento y dignidad en el que lograron construir, aunque solo fuera fugazmente como percibe Beltrán Roca, un mundo genuinamente democrático.

En el último capítulo, “¿Ley de hierro de la oligarquía? Posibilidades para la revitalización del sindicalismo combativo", el autor explica la desligitimación actual de los sindicatos -la mayor de los últimos treinta años- a través de la teoría de Míchels sobre las organizaciones que acaban tendiendo a ser estructuras jerárquicas, burocratizadas y poco participadas. Este proceso de pérdida de legitimidad se ha debido tanto a factores internos (derivados de su propia estructura y actuación), como externos (contexto social, político y económico). En la última década especialmente se ha producido, desde 
determinados ámbitos neoconservadores, una planificada ofensiva contra el sindicalismo que ha fraguado una imagen ciudadana muy negativa de los sindicatos. Roca desgrana con pormenorización muchas de las ideas estigmatizadoras que desde los medios de masas se difunden contra las organizaciones sindicales y termina el capítulo aportando una serie de propuestas para contribuir a la reflexión sobre el fortalecimiento del sindicalismo combativo. En este sentido, este capítulo concreto, y todo el libro, trasciende lo que podría considerarse un análisis erudito -aunque no deja de serlo- constreñido al ámbito académico. Las enseñanzas que aporta Beltrán Roca de manera sentida, amena y didáctica suponen una valiosa contribución para activistas sindicales -y ciudadanía en general- interesados en conocer los entresijos de la organización sindical contempránea, con el fin de transformarla en herramienta de emancipación de las clases trabajadoras y subalternas, que fue, en su origen, la causa para lo que fueron creadas. 